\title{
Antibiotics that bind to the A site of the large ribosomal subunit can induce mRNA translocation
}

\author{
DMITRI N. ERMOLENKO, ${ }^{1,5}$ PETER V. CORNISH, ${ }^{2}$ TAEKJIP HA, $^{3}$ and HARRY F. NOLLER ${ }^{4}$ \\ ${ }^{1}$ Department of Biochemistry and Biophysics and Center for RNA Biology, School of Medicine and Dentistry, University of Rochester, \\ Rochester, New York 14642, USA \\ ${ }^{2}$ Department of Biochemistry, University of Missouri, Columbia, Missouri 65211, USA \\ ${ }^{3}$ Department of Physics and Howard Hughes Medical Institute, University of Illinois, Urbana, Illinois 61801, USA \\ ${ }^{4}$ Department of Molecular, Cell and Developmental Biology and Center for Molecular Biology of RNA, University of California, \\ Santa Cruz, California 95064, USA
}

\begin{abstract}
In the absence of elongation factor EF-G, ribosomes undergo spontaneous, thermally driven fluctuation between the pretranslocation (classical) and intermediate (hybrid) states of translocation. These fluctuations do not result in productive mRNA translocation. Extending previous findings that the antibiotic sparsomycin induces translocation, we identify additional peptidyl transferase inhibitors that trigger productive mRNA translocation. We find that antibiotics that bind the peptidyl transferase A site induce mRNA translocation, whereas those that do not occupy the A site fail to induce translocation. Using single-molecule FRET, we show that translocation-inducing antibiotics do not accelerate intersubunit rotation, but act solely by converting the intrinsic, thermally driven dynamics of the ribosome into translocation. Our results support the idea that the ribosome is a Brownian ratchet machine, whose intrinsic dynamics can be rectified into unidirectional translocation by ligand binding.
\end{abstract}

Keywords: antibiotics; Brownian ratchet mechanism; mRNA translocation; ribosome

\section{INTRODUCTION}

During protein synthesis, mRNA and tRNAs are moved through the ribosome by the dynamic process of translocation. Sequential movement of tRNAs from the A (aminoacyl) site to the $\mathrm{P}$ (peptidyl) site to the $\mathrm{E}$ (exit) site is coupled to movement of their associated codons in the mRNA (Spirin 2004). Translocation is catalyzed by a universally conserved elongation factor (EF-G in prokaryotes and EF-2 in eukaryotes) (Spirin 2004).

Ribosomal translocation takes place in two steps, in which the acceptor ends of the tRNAs first move relative to the large ribosomal subunit (50S in bacteria), from the classical A/A and $\mathrm{P} / \mathrm{P}$ states into hybrid $\mathrm{A} / \mathrm{P}$ and $\mathrm{P} / \mathrm{E}$ states, followed by the movement of their anticodon ends on the small ribosomal subunit (30S), coupled with mRNA movement, into the posttranslocational $\mathrm{P} / \mathrm{P}$ and $\mathrm{E} / \mathrm{E}$ states (Fig. 1A; Moazed and Noller 1989). While hybrid state formation can occur spontaneously, translocation on the small subunit requires EF-G and GTP (Moazed and Noller 1989). Formation of the hybrid state intermediate is accompanied by a counterclockwise rotation of the small ribosomal subunit (Valle et al. 2003; Ermolenko et al. 2007a; Agirrezabala et al. 2008; Julian et al. 2008; Dun-

\footnotetext{
${ }^{5}$ Corresponding author

E-mail Dmitri_Ermolenko@urmc.rochester.edu

Article published online ahead of print. Article and publication date are at http://www.rnajournal.org/cgi/doi/10.1261/rna.035964.112.
}

kle et al. 2011). Blocking intersubunit rotation by formation of a disulfide cross-link abolishes translocation (Horan and Noller 2007). Single-molecule Förster Resonance Energy Transfer (smFRET) studies demonstrate that pre-translocation ribosomes undergo spontaneous intersubunit rotational movement in the absence of ribosomal factors and GTP (Cornish et al. 2008), fluctuating between two conformations corresponding to the classical and hybrid states of the tRNA translocational cycle (Fig. 1A; Blanchard et al. 2004; Ermolenko et al. 2007b; Munro et al. 2007; Fei et al. 2008). However, under most experimental conditions, in the absence of EF$\mathrm{G}$, these fluctuations do not result in productive translocation of mRNA and tRNAs on the small ribosomal subunit. EF-G transiently stabilizes the hybrid state conformation (Pan et al. 2007; Spiegel et al. 2007; Ermolenko and Noller 2011) and catalyzes mRNA translocation during the reverse (clockwise) rotation of the small subunit (Ermolenko and Noller 2011). mRNA translocation is likely accompanied by additional conformational changes within the small ribosomal subunit, i.e., "swiveling" motion of the "head" relative to the "body" and the "platform" of the 30S, which is orthogonal to the intersubunit rotation (Schuwirth et al. 2005; Ratje et al. 2010; Dunkle et al. 2011; Zhou et al. 2012). Despite recent progress in studies of the translocation mechanism, the question remains: How does EF-G convert unproductive spontaneous fluctuations of the ribosome and tRNAs into efficient translocation of tRNA and mRNA? 


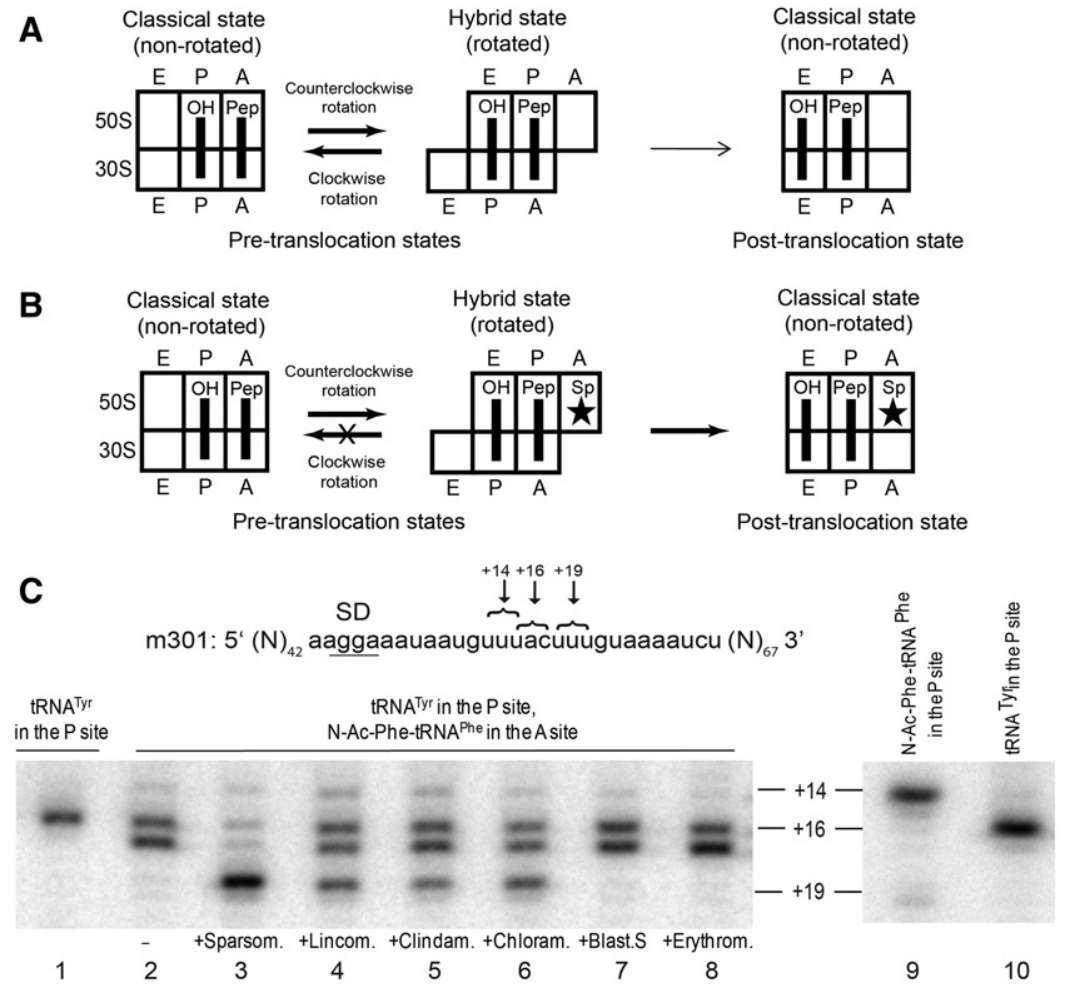

FIGURE 1. Antibiotic-induced translocation of mRNA. (A) Schematic depiction of intersubunit rotation and tRNA movement in pre-translocation ribosomes. (Movement of mRNA is not shown.) Under most experimental conditions, spontaneous, nonproductive forward and reverse intersubunit rotation, coupled to fluctuations between the classical and hybrid states of tRNA binding, does not result in mRNA translocation in the absence of EF-G. (B) Schematic illustration of hypothesized mechanism of sparsomycin-induced translocation (see details in the text). Binding of sparsomycin to the 50S A site is indicated by a star. $(C)$ Toeprinting assay of antibiotic-induced mRNA translocation. A pre-translocation complex was made by binding deacylated tRNA $^{\text {Tyr }}$ to the P site (lanes 1 and 10) and the peptidyl-tRNA analog N-Ac-Phe-tRNA ${ }^{\text {Phe }}$ to the A site (lane 2) in the presence of mRNA 301. Pre-translocation ribosomes were incubated with sparsomycin (lane 3), lincomycin (lane 4), clindamycin (lane 5), chloramphenicol (lane 6), blasticidin $\mathrm{S}$ (lane 7 ), and erythromycin (lane 8 ). A toeprint band at +16 corresponds to the pre-translocation complex, a band at +19 is the product of translocation, and a band at +14 is the product of direct binding of $N$-Ac-Phe-tRNA ${ }^{\text {Phe }}$ to the upstream Phe codon (lane 9).

The spontaneity of intersubunit rotational movement prompted several groups to apply the theoretical framework of the Brownian ratchet mechanism to the analysis of ribosomal translocation (Frank and Gonzalez 2010; Ratje et al. 2010; Dunkle et al. 2011). In Brownian ratchet models, unidirectional movement of macromolecules is enabled by ligand binding and chemical reactions that rectify spontaneous thermal fluctuations of macromolecules by preferentially locking in a preferred state (Howard 2006). (By "rectify," we mean conversion of movement, which periodically reverses direction, to unidirectional motion.) Thus, ligand binding is analogous to the pawl of a mechanical ratchet. However, the hypothesis that the ribosome is a Brownian ratchet machine whose spontaneous dynamics can be converted into translation (Spirin 2004; Frank and Gonzalez 2010; Ratje et al. 2010; Dunkle et al. 2011) has not been rigorously tested. Moreover, the exact nature of the pawl of the translocation ratchet and its mechanics is unknown.
Here, we exploit the use of antibiotics as an example of rectification of ribosomal dynamics via ligand binding. Previously, an intriguing translocation phenomenon was discovered: The antibiotic sparsomycin, a peptidyl transferase inhibitor that binds to the large ribosomal subunit, was found to induce efficient translocation of tRNA and mRNA on the small subunit (Fredrick and Noller 2003). Early studies on the inhibitory action of sparsomycin showed that it increases the affinity of tRNA for the P site while interfering with binding to the A site (Monro et al. 1969; Pestka 1969; Lazaro et al. 1991). Consistent with these findings, crystallographic studies of sparsomycin bound to the large ribosomal subunit showed that its uracil moiety interacts with the $3^{\prime}$-terminal cytosine and adenine of the P-site tRNA, while its sulfur-rich tail overlaps with the binding position of the aminoacyl moiety and terminal adenine of the A-site tRNA (Hansen et al. 2003). It was originally hypothesized that sparsomycin induces translation by stabilization of the posttranslocation state of the ribosome via interaction with peptidyl-tRNA in the 50S P site (Fredrick and Noller 2003). However, the observation that spontaneous movement of the acceptor ends of tRNAs on the large subunit does not result in efficient translocation on the small subunit (Fig. 1A; Moazed and Noller 1989; Blanchard et al. 2004; Fei et al. 2008) suggests that this explanation may be insufficient. An alternative possibility is that sparsomycin induces ribosomal translocation by sterically blocking the reverse movement of peptidyl-tRNA from the hybrid A/P to the classical A/A state as the ribosome spontaneously fluctuates between the rotated and nonrotated conformations (Fig. 1B). In this model, sparsomycin plays the role of a pawl in a Brownian ratchet. To test this possibility, we examined the ability of other antibiotics that bind to the 50S A site but are chemically different from sparsomycin, to induce mRNA translocation.

\section{RESULTS}

\section{Antibiotics that bind to the 50S A site induce mRNA translocation}

Biochemical and crystallographic studies have identified several peptidyl transferase inhibitors that bind to the A site of 
the large subunit, including chloramphenicol, puromycin, and the lincosamides lincomycin and clindamycin (Schlunzen et al. 2001; Hansen et al. 2003; Wilson 2009; Bulkley et al. 2010; Dunkle et al. 2010). These antibiotics compete for 50S A-site binding with each other as well as with aminoacylated oligonucleotide fragments corresponding to the $3^{\prime}$ terminus of aminoacyl-tRNA (Celma et al. 1971; Fernandez-Munoz et al. 1971; Contreras and Vazquez 1977; Wilson 2009). We tested the ability of chloramphenicol, lincomycin, clindamycin, and puromycin to induce translocation using a toeprinting assay, which uses primer extension to monitor mRNA movement on the ribosome (Fig. 1C; Joseph and Noller 1998). Binding of the defined m301 mRNA (Fredrick and Noller 2003) and deacylated tRNA ${ }^{\text {Tyr }}$ produced a toeprint band corresponding to position +16 , indicating the positioning of the Tyr codon UAC in the ribosomal P site by tRNA ${ }^{\text {Tyr }}$ (Fig. 1C, lane 1) $(+16$ corresponds to the position on the mRNA relative to the first nucleotide of the P-site codon where reverse transcriptase stops upon encountering the ribosome). Addition of the peptidyltRNA analog $N$-Ac-Phe-tRNA ${ }^{\text {Phe }}$ resulted in formation of a pre-translocation complex, as evidenced by the appearance of a doublet band indicative of peptidyl-tRNA binding to the A site (Fig. 1C, lane 2; Joseph and Noller 1998). Incubation of the pre-translocation complex with sparsomycin shifted the toeprint stop to position +19 , indicating translocation of mRNA by one codon, in agreement with previous observations (Fig. 1C, lane 3; Fredrick and Noller 2003). Incubation of pre-translocation ribosomes with lincomycin, clindamycin, or chloramphenicol also resulted in appearance of a stop at position +19 (Fig. 1C, lanes 4-6; Fig. 2). The m301 sequence contains an upstream UUU codon overlapping with the tyrosine codon UAC (Fig. 1C). Since this UUU codon is positioned more optimally with respect to the Shine-Dalgarno sequence, it is preferentially used over the downstream UUU codon when $N$-Ac-Phe-tRNA ${ }^{\text {Phe }}$ is bound directly to the $\mathrm{P}$ site (Fredrick and Noller 2003), evidenced by appearance of a +14 toeprint stop (Fig. 1C, lane 9). Thus, the appearance of the +19 toeprint induced by the $50 \mathrm{~S}$ A-site antibiotics corresponds to authentic mRNA translocation and cannot be explained by the possibility of dissociation and reassociation of ribosomal complexes.

The extent of mRNA translocation in the presence of lincomycin, clindamycin, and chloramphenicol varied from $40 \%$ for clindamycin to $60 \%$ for lincomycin, less efficient than sparsomycin-induced translocation (near 90\% complete), but dramatically enhanced relative to spontaneous translocation, which was virtually undetectable. The 50S Asite binding antibiotic puromycin also reproducibly stimulated translocation in $15 \%-20 \%$ of ribosomes (Fig. 2A, lane 7). However, we excluded puromycin from further analysis because of its significantly lower translocation efficiency, relative to other A-site antibiotics. The antibiotics blasticidin S and erythromycin, which bind to the $\mathrm{P}$ site in the peptidyl transferase cavity (Hansen et al. 2003) and in the peptide

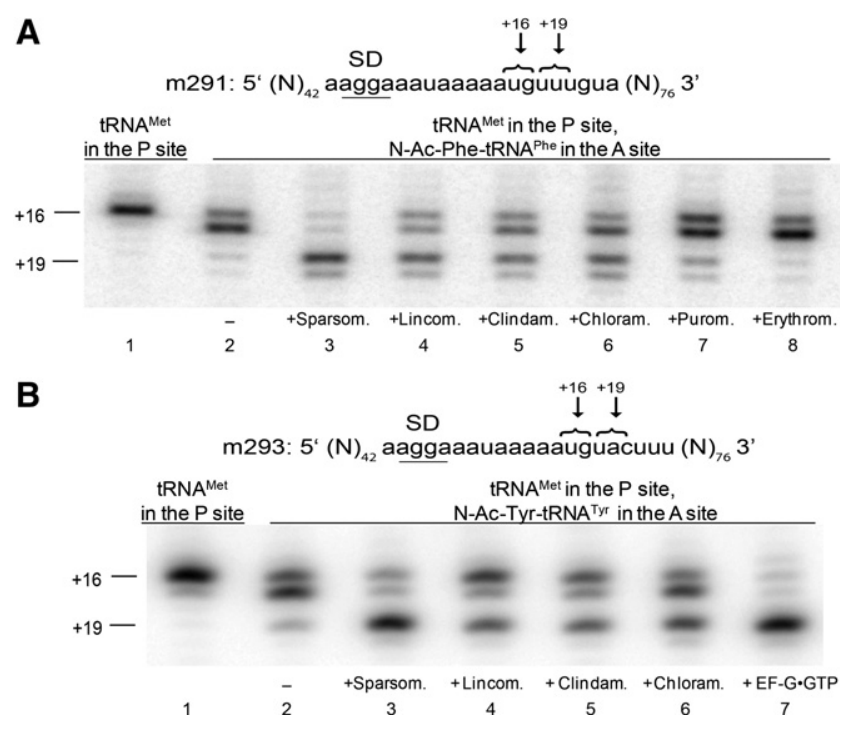

FIGURE 2. Antibiotic-induced translocation of different mRNA and tRNA species. (A) A pre-translocation complex made by binding deacylated tRNA ${ }^{\mathrm{Met}}$ to the P site (lane 1 ) and the peptidyl-tRNA analog $N$-AcPhe-tRNA ${ }^{\text {Phe }}$ to the A site (lane 2) in the presence of mRNA 291 was incubated with sparsomycin (lane 3), lincomycin (lane 4), clindamycin (lane 5), chloramphenicol (lane 6), puromycin (lane 7), or erythromycin (lane 8 ). (B) A pre-translocation complex made by binding deacylated tRNA ${ }^{\text {Met }}$ to the P site (lane 1 ) and peptidyl-tRNA analog $N$-AcTyr-tRNA ${ }^{\text {Tyr }}$ to the A site (lane 2) in the presence of mRNA 293 was incubated with sparsomycin (lane 3), lincomycin (lane 4), clindamycin (lane 5), chloramphenicol (lane 6), or EF-G and GTP (lane 7).

exit tunnel (Schlunzen et al. 2001), respectively, but do not occupy the A site fail to induce mRNA translocation (Fig. 1C, lanes 7,8; Fig. 2A, lane 8). Therefore, only those peptidyl-transferase inhibitors that bind to the 50S A site were found to induce mRNA translocation.

\section{Properties of antibiotic-induced translocation}

Lincomycin, clindamycin, and chloramphenicol promoted translocation of a variety of different mRNA and tRNA combinations: mRNA m301 with tRNA $^{\text {Tyr }}$ and N-Ac-PhetRNA $^{\text {Phe }}$ (Fig. 1C); m291 (Fredrick and Noller 2002) with tRNA $^{\text {Met }}$ and N-Ac-Phe-tRNA ${ }^{\text {Phe }}$ (Fig. 2A); and $\mathrm{m} 293$ (Fredrick and Noller 2002) with tRNA ${ }^{\text {Met }}$ and N-Ac-TyrtRNA $^{\text {Tyr }}$ (Fig. 2B). Thus, A-site binding antibiotics induce translocation regardless of the identity of $\mathrm{A}$ - and $\mathrm{P}$-site tRNA species.

Crystallographic studies showed that the sulfur-rich tail moiety of sparsomycin, the prolyl moiety of clindamycin, and the nitrobenzene moiety of chloramphenicol clash with the aminoacyl moiety of A-site tRNA (Hansen et al. 2003; Bulkley et al. 2010; Dunkle et al. 2010). Accordingly, we next tested whether the A-site antibiotics can induce translocation in pre-translocation ribosomes containing deacylated tRNA in the A site. When A-site peptidyl-tRNA was replaced with deacylated tRNA, the ability of lincomycin, 


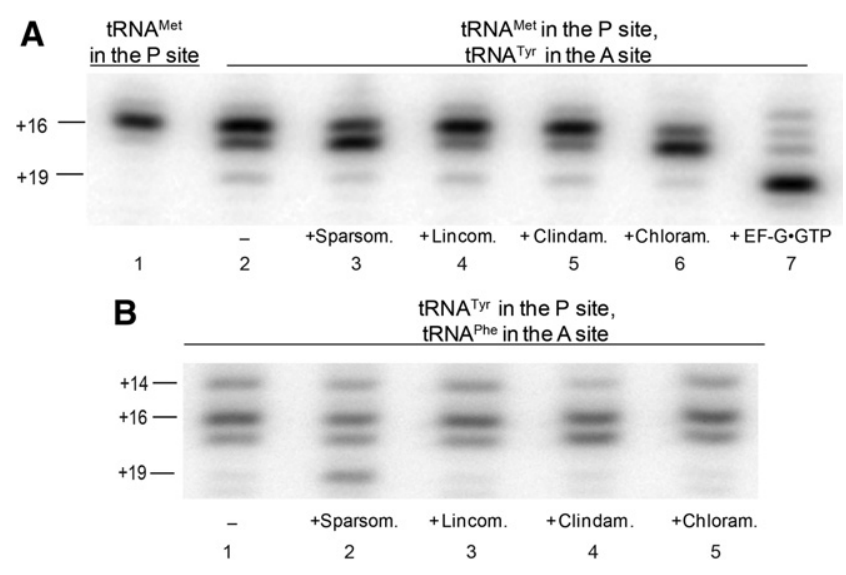

FIGURE 3. Translocation of complexes containing deacylated A-site tRNA. (A) A pre-translocation complex made by binding deacylated tRNA $^{\text {Met }}$ to the P site (lane 1 ) and deacylated tRNA ${ }^{\text {Tyr }}$ to the A site (lane 2) in the presence of mRNA 293 was incubated with sparsomycin (lane 3), lincomycin (lane 4), clindamycin (lane 5), chloramphenicol (lane 6), or EF-G and GTP (lane 7). (B) A pre-translocation complex made by binding deacylated tRNA ${ }^{\text {Tyr }}$ to the $\mathrm{P}$ site and deacylated tRNA $^{\text {Phe }}$ to the A site in the presence of mRNA 301 (lane 1) was incubated with sparsomycin (lane 2), lincomycin (lane 3), clindamycin (lane 4), and chloramphenicol (lane 5).

clindamycin, and chloramphenicol to induce translocation was completely abolished (Fig. 3). The efficiency of sparsomycin-induced translocation also dramatically decreased (Fig. 3). In contrast, EF-G-catalyzed translocation remained complete (Fig. 3A, lane 7). Therefore, antibiotic-induced translocation requires the presence of an aminoacyl moiety at the A-site tRNA.

Sparsomycin-, chloramphenicol-, lincomycin-, and clindamycin-induced translocation was completely eliminated in the presence of antibiotics viomycin and hygromycin $\mathrm{B}$, which are known to inhibit EF-Gcatalyzed translocation without hindering EF-G binding or GTP hydrolysis (Fig. 4A; Peske et al. 2004). Viomycin and hygromycin $\mathrm{B}$ bind $>50 \AA$ away from the peptidyl-transferase cavity at the intersubunit interface and decoding site of the small subunit, respectively, and therefore cannot directly compete with peptidyl-transferase inhibitors for binding (Borovinskaya et al. 2008; Stanley et al. 2010). The inhibition of antibiotic-induced translocation by viomycin and hygromycin B provides evidence for underlying similarities between the mechanisms of antibiotic- and EF-Gdependent translocation.
Using the toeprinting assay, we measured the kinetics of antibiotic-induced translocation, facilitated by terminating the translocation reaction at various time points with viomycin (Fig. 4B; Fredrick and Noller 2003). Fitting of the kinetic data to single exponentials gave apparent first-order rate constants of $0.04 \mathrm{~min}^{-1}, 0.03 \mathrm{~min}^{-1}$, and $0.08 \mathrm{~min}^{-1}$ for lincomycin, clindamycin, and chloramphenicol, respectively. Although these rates are about fivefold to 10 -fold slower than that of sparsomycin-induced translocation (0.4 $\min ^{-1}$ ) (Fig. 4B; Fredrick and Noller 2003), they are about two orders of magnitude faster than the estimated rate of $0.8 \times 10^{-3} \mathrm{~min}^{-1}$ for spontaneous translocation (Fig. 4B; Fredrick and Noller 2003). The extent of translocation also depended on antibiotic concentration (Fig. 4C). Maximum translocation efficiency was achieved at $\sim 200 \mu \mathrm{M}$ chloramphenicol or lincomycin. Further increases in antibiotic concentration did not lead to an increase in the fraction of translocated mRNA (Fig. 4C). It is not immediately clear why translocation in the presence of chloramphenicol and lincomycin does not reach completion. Possible explanations are considered in the Discussion below. Nevertheless, our results unambiguously demonstrate the ability of A-site binding antibiotics to significantly stimulate mRNA translocation.

\section{Effect of peptidyl-transferase inhibitors on intersubunit movement}

We next tested whether sparsomycin, lincomycin, and chloramphenicol affected the equilibrium between the rotated and

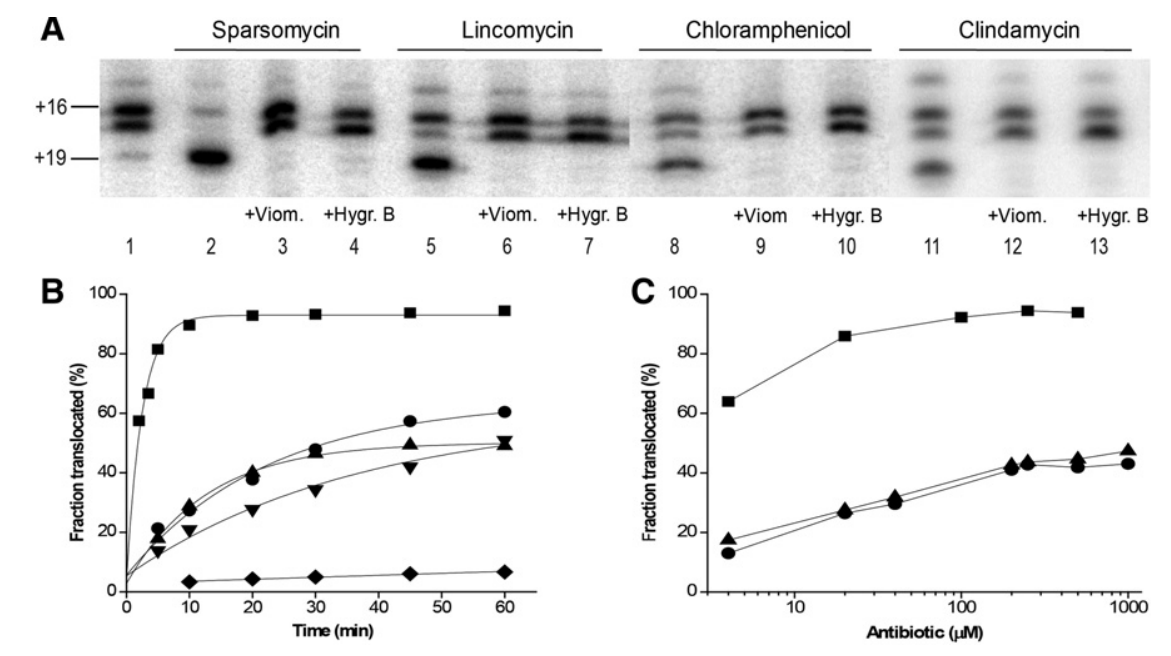

FIGURE 4. Characterization of antibiotic-induced mRNA translocation. (A) Inhibition of antibiotic-induced translocation by viomycin and hygromycin B. Pre-translocation ribosomes containing deacylated tRNA ${ }^{\mathrm{Tyr}}$ in the P site and N-Ac-Phe-tRNA ${ }^{\mathrm{Phe}}$ in the A site (lane 1) were first pre-incubated with the translocation inhibitors viomycin (lanes 3,6,9,12) or hygromycin B (lanes 4,7,10,13) and then incubated with sparsomycin (lanes 2-4), lincomycin (lanes 5-7), chloramphenicol (lanes 8 10), or clindamycin (lanes $11-13$ ) for $30 \mathrm{~min}$ at $37^{\circ} \mathrm{C}$. In control experiments (lanes $2,5,8,11$ ), no translocation inhibitor was added. $(B)$ Kinetics of mRNA translocation in the presence of sparsomycin $(\bullet)$, lincomycin $(\bullet)$, chloramphenicol $(\boldsymbol{\Delta})$, or clindamycin $(\boldsymbol{\nabla})$. ( $\bullet)$ Spontaneous translocation in the absence of antibiotics. (Black lines) Single exponential fits. $(C)$ Dependence of mRNA translocation $\left(30 \mathrm{~min}\right.$ at $\left.37^{\circ} \mathrm{C}\right)$ on concentration of sparsomycin $(\boldsymbol{\bullet})$, lincomycin $(\bullet)$, or chloramphenicol $(\mathbf{\Lambda})$. 
nonrotated conformations of the ribosome and accelerated the rates of intersubunit rotation, which underlie ribosomal translocation. We previously developed a method to follow intersubunit movement of the ribosome by measuring smFRET between fluorophores attached to protein S6 on the platform of the small subunit and protein L9 on the large subunit, which is juxtaposed with S6 across the subunit interface. Using this assay in combination with total internal reflection microscopy, we previously demonstrated spontaneous fluctuation of single pre-translocation ribosomes between FRET values of 0.6 and 0.4 that correspond to the nonrotated (classical) and rotated (hybrid) states, respectively (Fig. 1A). Measurement of the effects of antibiotics on the structural dynamics of pre-translocation ribosomes is complicated by the translocation induced by binding of the antibiotic. To overcome this problem, we used fluorescently labeled complexes containing a single deacylated tRNA bound to the $\mathrm{P}$ site, since translocation requires the presence of tRNAs in both the A and P sites (Joseph and Noller 1998). Our previous smFRET experiments demonstrated that the intersubunit dynamics of ribosomes containing a single deacylated tRNA in the $\mathrm{P}$ site and authentic pre-translocation complexes are very similar (Cornish et al. 2008). Consistent with our previous results, a majority $(85 \% \pm 5 \%)$ of ribosomes containing tRNA ${ }^{\mathrm{Tyr}}$ in the $\mathrm{P}$ site were in the rotated (0.4 FRET) state (Fig. 5A), frequently transitioning into the nonrotated (0.6 FRET) conformation and back, at a rate of $0.3 \mathrm{sec}^{-1}$ (Fig. 6; Table 1). Neither chloramphenicol nor lincomycin significantly affected these intersubunit dynamics (Fig. 5B,C; Table 1). In contrast, in the presence of sparsomycin, only $30 \%$ of the ribosomes were observed in the rotated conformation (Fig. 5D). Sparsomycin binding caused a 20-fold decrease in the rate of counterclockwise rotation without affecting the rate of clockwise rotation (Table 1). Sparsomycin was shown to enhance binding of tRNA to the 50S P site via interaction with the two $3^{\prime}$-terminal nucleotides of tRNA (Hansen et al. 2003; Wilson 2009). Thus, sparsomycin appears to favor binding of the deacylated tRNA in the classical $\mathrm{P} / \mathrm{P}$ state in the nonrotated conformation of the ribosome. Nevertheless, sparsomycin-bound ribosomes remain highly dynamic, fluctuating between the nonrotated (classical) and rotated (hybrid) states at a rate of $0.1-0.3$ $\sec ^{-1}$ (Fig. 6; Table 1) that is at least 10 -fold faster than the rate of intersubunit rotation in post-translocation ribosomes, which are predominantly fixed in the nonrotated conformation (Cornish et al. 2008). Taken together, our smFRET data suggest that translocation-inducing antibiotics do not accelerate intersubunit rotation, but act solely by converting the intrinsic, thermally driven dynamics of the ribosome into translocation.

\section{DISCUSSION}

The results of our toeprinting and smFRET experiments show that spontaneous intersubunit rotation of the ribosome can be rectified into unidirectional translocation by binding of antibiotics to the A site. We observe that the ability to induce translocation is not unique to sparsomycin; other chemically distinct peptidyl-transferase inhibitors, which bind to the 50S A site, such as chloramphenicol, and the lincosamides lincomycin and clindamycin, can induce translocation.

The translocation potency of the A-site antibiotics varies dramatically. While sparsomycin induces translocation in $>90 \%$ of ribosomes, translocation in the presence of lincosamides and chloramphenicol remains incomplete, even at saturating concentrations of these antibiotics (Fig. 4C) and prolonged incubation times, where the kinetics of translocation reach a plateau (Fig. 4B). Translocation in the presence of puromycin is even less efficient (Fig. 2). No translocation was observed in the presence of linezolid, another A-sitebinding antibiotic ( $\mathrm{Li}$ et al. 2011). There may be several factors that contribute to the decreased translocation potency of other A-site antibiotics in comparison to sparsomycin. Stabilization of peptidyl-tRNA binding to the $50 \mathrm{~S} \mathrm{P}$ site
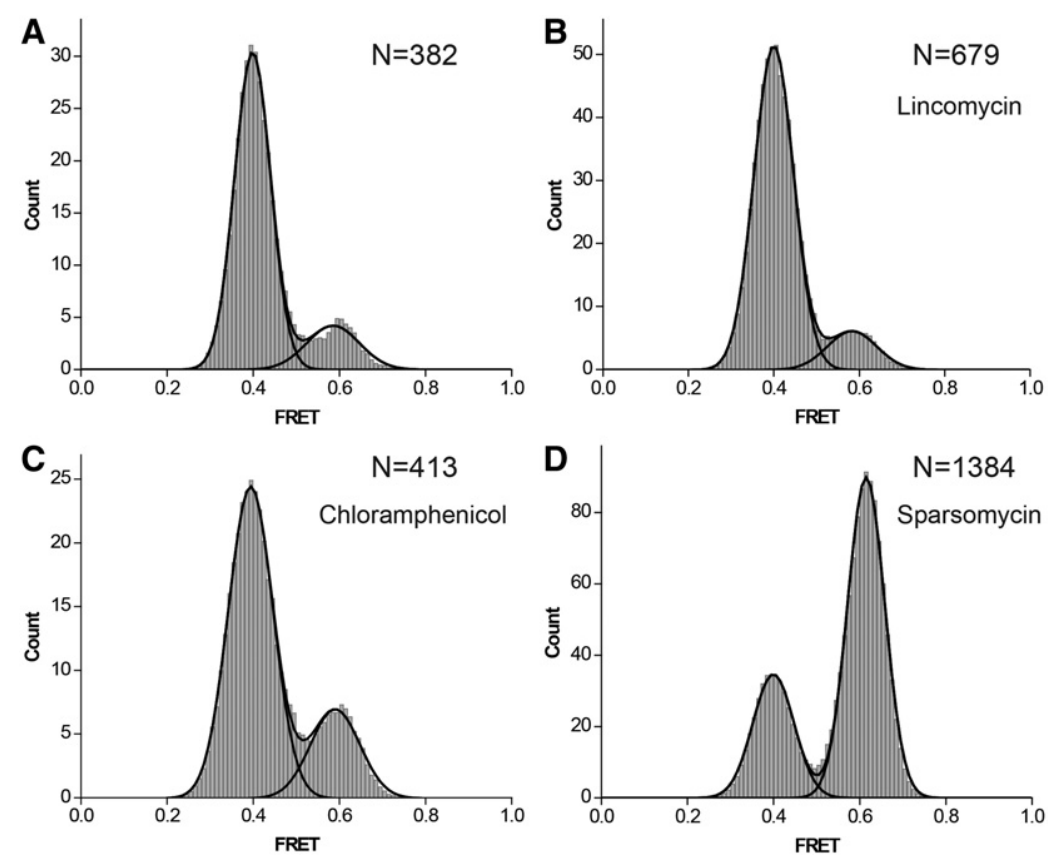

FIGURE 5. Histograms showing distribution of FRET values in different ribosomal complexes. S6-Cy5/L9-Cy3 ribosomes were assembled with mRNA (m301) and deacylated tRNA ${ }^{\text {Tyr }}$ in the P site $(A)$ and incubated with lincomycin $(B)$, chloramphenicol $(C)$, or sparsomycin $(D) . N$ is the number of single-molecule traces compiled. 

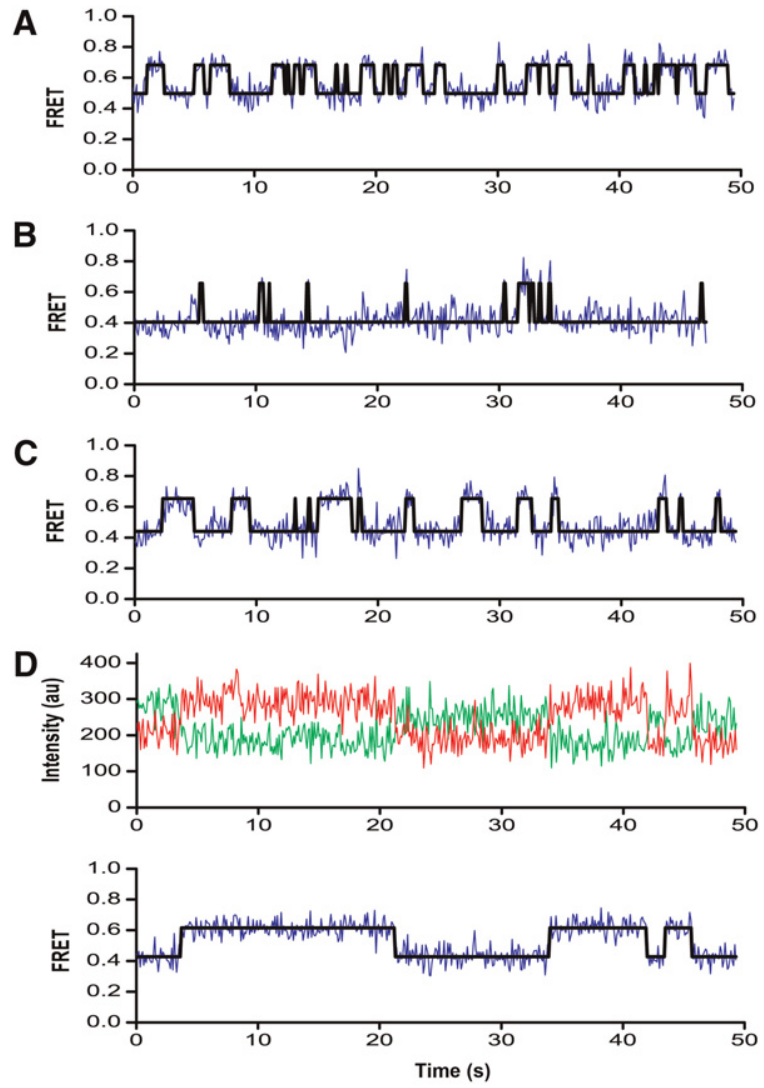

FIGURE 6. Representative FRET time trajectories of intersubunit movement. Traces show fluorescence intensities observed for $\mathrm{Cy} 3$ (green) on ribosomal protein L9 and Cy5 (red) on ribosomal protein S6 and the calculated FRET traces (blue). The fitted curves obtained by Hidden Markov Modeling (HMM) analysis (black) are superimposed on the FRET trajectories. Fluorescence intensities are only shown for the complex in panel $D$. 70S ribosomes containing tRNA ${ }^{\mathrm{Tyr}}$ in the $\mathrm{P}$ site $(A)$ were incubated with lincomycin $(B)$, chloramphenicol $(C)$, or sparsomycin $(D)$.

through interaction with the uracil moiety of sparsomycin (Figs. 5, 6; Hansen et al. 2003; Wilson 2009) may increase the efficiency of sparsomycin-induced translocation in comparison to other translocation-inducing antibiotics that interact with the 50S A site only. Moreover, the overlap of the sulfur-rich tail of sparsomycin with the 50S A site is more extensive than the structural overlap observed for the other antibiotics. Sparsomycin clashes with both the aminoacyl moiety and the $3^{\prime}$ adenine of the A-site tRNA, while all the other A-site antibiotics overlap only with the aminoacyl moiety (Hansen et al. 2003; Bulkley et al. 2010; Dunkle et al. 2010). Consistent with this observation, sparsomycin is the only antibiotic that induced a detectable level of translocation of deacylated A-site tRNA (Fig. $3 \mathrm{~B}$, lane 2). Furthermore, the transloca- tion efficiency of A-site antibiotics appears to correlate loosely with their affinity for the ribosome, decreasing from sparsomycin $\left(K_{\mathrm{d}}<1 \mu \mathrm{M}\right)$ (Lazaro et al. 1987) to chloramphenicol $\left(K_{\mathrm{d}} \sim 2-6 \mu \mathrm{M}\right)$ (Contreras and Vazquez 1977) and the lincosamides $\left(K_{\mathrm{d}} \sim 4-6 \mu \mathrm{M}\right.$ ) (Contreras and Vazquez 1977; Douthwaite 1992) to linezolid $\left(K_{\mathrm{d}} \sim 20 \mu \mathrm{M}\right)$ (Lin et al. 1997) and puromycin $\left(K_{\mathrm{d}} \sim 3-4 \mathrm{mM}\right)$ (Wohlgemuth et al. 2006). Recently, it has been demonstrated that while neither linezolid nor the pseudouridine moiety of sparsomycin, which binds to the A and P sites of large subunit, respectively, can stimulate mRNA translocation by themselves, a linezolid-pseudouridine conjugate can induce translocation in a fraction of ribosomes (Li et al. 2011). Conjugation of linezolid with the pseudouridine moiety of sparsomycin likely enhances the translocation potency of linezolid by increasing its binding affinity for the ribosome.

In addition to binding affinity, other factors may affect the translocation efficiencies of A-site antibiotics. Binding of an antibiotic to the 50S A site may trigger two competing processes: translocation of the A-site tRNA or its dissociation from the ribosome. Indeed, when we measured retention of A-site tRNA using a filter binding assay, dissociation of $N$-Ac-Phe-tRNA ${ }^{\text {Phe }}$ from the A site was observed for 30\%$40 \%$ of ribosomes after incubation of pre-translocation ribosome complexes with lincomycin or clindamycin (Fig. 7). The translocation potency of puromycin may also be affected by the ribosome-catalyzed transpeptidation reaction between peptidyl-tRNA bound to the A/P hybrid state and puromycin itself, which results in deacylation of peptidyl-tRNA. However, this is unlikely to be the main factor determining the low translocation potency of puromycin, since previous experiments have shown that it reacts poorly with the peptidyl-tRNA analogs used in this work (such as NAc-PhetRNA $^{\text {Phe }}$ and NAc-Tyr-tRNA ${ }^{\text {Tyr }}$ ), bound to the A site of pre-translocation ribosomes (Moazed and Noller 1989; Spiegel et al. 2007).

Despite differences in translocation efficiency, A-sitebinding antibiotics evidently promote translocation. Although the ability to induce translocation is unlikely to contribute to the antimicrobial activity of these antibiotics, which are known to be potent inhibitors of the peptidyl-
TABLE 1. Proportions of rotated and nonrotated ribosomes and rates of spontaneous interconversion in the presence of antibiotics, from smFRET

\begin{tabular}{lcccc}
\hline Antibiotic & Percent R & Percent NR & $k_{0.6 \rightarrow 0.4}\left(\mathrm{sec}^{-1}\right)$ & $k_{0.4 \rightarrow 0.6}\left(\mathrm{sec}^{-1}\right)$ \\
\hline None & 85 & 15 & $2.34 \pm 0.59$ & $0.28 \pm 0.08$ \\
Lincomycin & 87 & 13 & $2.32 \pm 0.86$ & $0.22 \pm 0.20$ \\
Chloramphenicol & 76 & 24 & $1.75 \pm 0.71$ & $0.43 \pm 0.44$ \\
Sparsomycin & 30 & 70 & $0.11 \pm 0.08$ & $0.31 \pm 0.27$ \\
\hline
\end{tabular}

Percent of pre-translocation ribosomes in nonrotated (NR), 0.6 FRET state, or rotated (R), 0.4 FRET state derived from FRET distribution histograms (Fig. 5). The standard deviation was $5 \%$. Rates of counterclockwise $\left(k_{0.6 \rightarrow 0.4}\right)$ and clockwise $\left(k_{0.4 \rightarrow 0.6}\right)$ intersubunit rotation are calculated from HMM analysis as described in Materials and Methods. The standard deviation values are derived from fitting the collected rates to a Gaussian distribution. 


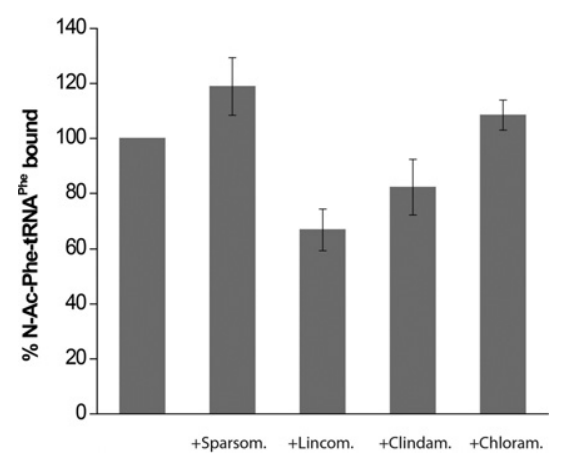

FIGURE 7. Dissociation of $N$-Ac-Phe-tRNA ${ }^{\text {Phe }}$ from the A site in the presence of peptidyl-transferase inhibitors. Pre-translocation ribosomes were assembled by binding deacylated tRNA ${ }^{\text {Met }}$ to the $\mathrm{P}$ site and the peptidyl-tRNA analog N-Ac- $\left[{ }^{3} \mathrm{H}\right] \mathrm{Phe}$-tRNA ${ }^{\text {Phe }}$ to the A site in the presence of mRNA, as in Figure 2A, and incubated for $30 \mathrm{~min}$ at $37^{\circ} \mathrm{C}$ with sparsomycin, lincomycin, clindamycin, or chloramphenicol, as indicated. Histograms show the percentage of $\mathrm{N}$-Ac- $\left[{ }^{3} \mathrm{H}\right]$ Phe-tRNA ${ }^{\text {Phe }}$ bound to the A site relative to that in ribosomes untreated with antibiotics. The amount of Ac- $\left[{ }^{3} \mathrm{H}\right]$ Phe-tRNA ${ }^{\text {Phe }}$ bound to the ribosome was detected by a filter-binding assay. Sparsomycin slightly stabilizes binding of Ac$\left[{ }^{3} \mathrm{H}\right] \mathrm{Phe}-\mathrm{tRNA}{ }^{\mathrm{Phe}}$ to post-translocation ribosomes in comparison to ribosomes untreated with antibiotics.

transferase activity of the ribosome, the phenomenon of antibiotic-induced translocation provides an important insight into the mechanism of ribosome translocation. Several lines of evidence support the hypothesis that they induce translocation by sterically blocking the reverse movement of peptidyl-tRNA from the hybrid A/P to the classical A/A state as the ribosome spontaneously fluctuates between the rotated and nonrotated conformations. The antibiotics blasticidin S and erythromycin, which bind in the peptidyl transferase cavity but do not occupy the A site, do not induce mRNA translocation (Figs. 1, 2). A-site binding antibiotics that predominately clash with the aminoacyl moiety of the A-site tRNA failed to induce translocation of deacylated A-site tRNA (Fig. 3). Furthermore, isomerization of the sulfurrich tail of sparsomycin, which interacts with the 50S A site, was recently shown to significantly decrease the ability of sparsomycin to induce translocation (Li et al. 2011). Thus, our results support the idea that the ribosome is a Brownian ratchet machine whose spontaneous fluctuation can be rectified into translocation by ligand binding.

Although EF-G accelerates translocation by $10^{3}$-fold to $10^{4}$-fold more than the A-site antibiotics (Rodnina et al. 1997), it may operate through an analogous mechanism, serving as a pawl in a Brownian ratchet mechanism (Frank and Gonzalez 2010; Ratje et al. 2010). Indeed, in cryo-EM reconstructions of EF-G-ribosome complexes (Valle et al. 2003; Ratje et al. 2010), as well as in a recent crystal structure of EF-G bound to a nonrotated, classical-state ribosome (Gao et al. 2009), domain IV of EF-G, which has been shown to be essential for catalysis of translocation (Rodnina et al. 1997; Martemyanov et al. 1998), overlaps with the A site of the small ribosomal subunit. Thus, one role of domain IV of
EF-G could be to prevent the return of tRNA back into the 30S A site during translocation.

\section{MATERIALS AND METHODS}

\section{Preparation of ribosomes and ribosomal ligands}

$\mathrm{tRNA}^{\text {Phe }}$, $\mathrm{tRNA}^{\mathrm{Tyr}}$, and $\mathrm{tRNA}^{\mathrm{Met}}$ were purchased from SigmaAldrich. N-Ac-Phe-tRNA ${ }^{\text {Phe }}$ and EF-G with 6-histidine tag were prepared and purified as previously described (Moazed and Noller 1989; Wilson and Noller 1998; Dorner et al. 2006). Tight-couple 705 ribosomes and ribosomal subunits were prepared from Escherichia coli MRE600 as previously described (Lancaster et al. 2002; Hickerson et al. 2005). Cy5-labeled protein S6 was incorporated into $30 \mathrm{~S}$ subunits by in vitro reconstitution from purified $16 \mathrm{~S}$ rRNA and the other 19 individually purified ribosomal proteins according to published procedures (Culver and Noller 1999; Hickerson et al. 2005). Cy3-labeled protein L9 was incorporated into $50 \mathrm{~S}$ subunits by partial reconstitution from $50 \mathrm{~S}$ subunits carrying an L9 deletion, and doubly labeled 70S ribosomes were isolated using previously described procedures (Ermolenko et al. 2007a). The components of the oxygen-scavenging system (glucose oxidase from Aspergillus niger, glucose, and 6-hydroxy-2,5,7,8-tetramethylchromane-2-carboxylic acid) were purchased from Sigma-Aldrich. Catalase from beef liver was from Roche.

\section{Toeprinting analysis}

Toeprinting experiments were performed as previously described (Fredrick and Noller 2002; Spiegel et al. 2007). The pre-translocation complex was assembled by incubating 70 S ribosomes $(1 \mu \mathrm{M})$ with deacylated tRNA $(2 \mu \mathrm{M})$ and mRNA $(2 \mu \mathrm{M})$ pre-annealed to $\left[{ }^{32} \mathrm{P}\right]$-labeled primer (Fredrick and Noller 2002) in buffer A containing $30 \mathrm{mM}$ HEPES.KOH ( $\mathrm{pH} 7.5), 20 \mathrm{mM} \mathrm{MgCl} 2,100 \mathrm{mM}$ $\mathrm{NH}_{4} \mathrm{Cl}$, and $6 \mathrm{mM} \beta$-mercaptoethanol for $20 \mathrm{~min}$ at $37^{\circ} \mathrm{C}$. A-site tRNA $(2 \mu \mathrm{M})$ was added to P-site tRNA-bound complexes followed by incubation for $30 \mathrm{~min}$ at $37^{\circ} \mathrm{C}$. Ribosomal complexes were diluted to a final concentration of $0.5 \mu \mathrm{M}$ with buffer A lacking $\mathrm{MgCl}_{2}$ to adjust $\mathrm{Mg}$ concentration to $10 \mathrm{mM}$. Translocation was carried out by incubation of pre-translocation complexes with A-site binding antibiotics or 1.5 $\mu \mathrm{M}$ EF-G and $0.5 \mathrm{mM}$ GTP (Figs. 2, 3) for 20 (Fig. 1C) or 30 (Figs. 2-4) $\mathrm{min}$ at $37^{\circ} \mathrm{C}$. The concentration of sparsomycin was $0.5 \mathrm{mM}$; all other A-site binding antibiotics were $5 \mathrm{mM}$. The position of the ribosome along the mRNA was monitored using a primer-extension reaction as described previously (Fredrick and Noller 2002). In the experiments from Figure $4 \mathrm{~A}$, pre-translocation ribosomes were pre-incubated with the antibiotics viomycin $(1 \mathrm{mM})$ or hygromycin $\mathrm{B}(1 \mathrm{mM})$. Viomycin $(1 \mathrm{mM})$ was used to stop the translocation reaction in kinetic experiments (Fig. 4C).

\section{smFRET data acquisition and analysis}

Ribosomal complexes were constructed in buffer containing $20 \mathrm{mM}$ HEPES KOH ( $\mathrm{pH} 7.5$ ), $6 \mathrm{mM} \mathrm{MgCl}_{2}, 150 \mathrm{mM} \mathrm{NH} 4 \mathrm{Cl}, 6 \mathrm{mM}$ $\beta$-mercaptoethanol, $2 \mathrm{mM}$ spermidine, and $0.1 \mathrm{mM}$ spermine. Ribosome P-site tRNA mRNA complexes were constructed by incubation of 70 S ribosomes $(0.3 \mu \mathrm{M})$ with mRNA m301 $(0.6 \mu \mathrm{M})$ pre-annealed to biotin-labeled primer $(0.8 \mu \mathrm{M})$ and tRNA $^{\text {Tyr }}$ 
$(0.7 \mu \mathrm{M})$ for $20 \mathrm{~min}$ at $37^{\circ} \mathrm{C}$. All complexes were subsequently diluted to a final concentration of $\sim 2 \mathrm{nM}$ and were immobilized on the quartz surface of microscope slides prepared for these experiments using an established protocol (Zhuang et al. 2000). To prevent photobleaching during data acquisition, the sample buffer was exchanged for imaging buffer, containing an oxygen scavenging system $\left(20 \mathrm{mM}\right.$ HEPES $\mathrm{KOH}$ at $\mathrm{pH} 7.5,6 \mathrm{mM} \mathrm{MgCl}_{2}, 150 \mathrm{mM}$ $\mathrm{NH}_{4} \mathrm{Cl}, 6 \mathrm{mM} \beta$-mercaptoethanol, $2 \mathrm{mM}$ spermidine, $0.1 \mathrm{mM}$ spermine, $0.8 \mathrm{mg} / \mathrm{mL}$ glucose oxidase, $0.625 \%$ glucose, $\sim 1.5 \mathrm{mM}$ 6-hydroxy-2,5,7,8-tetramethylchromane-2-carboxylic [Trolox] and $0.03 \mathrm{mg} / \mathrm{mL}$ catalase) (Rasnik et al. 2006). Data were acquired and analyzed as previously described (Cornish et al. 2008). The time binning of the data was set at $100 \mathrm{msec}$. The resultant image files were processed using IDL software and analyzed using MatLab. Time traces were selected from the data set by choosing only traces that contained single photobleaching steps for Cy3 and Cy5. Furthermore, fluorescence blinking events, although extremely rare, were removed by truncating the traces prior to the blinking event. Histograms were created from the selected traces and smoothed with a 5-point window. Histograms were fit to Gaussian distributions using Origin. The peak position was left unrestrained. HaMMy was used for Hidden Markov Modeling (HMM) analysis of the FRET data (McKinney et al. 2006).

\section{ACKNOWLEDGMENTS}

We thank G. Culver and A. Korostelev for helpful discussions. These studies were supported by grants from the US National Institute of Health no. GM-099719 (to D.N.E.), P30 GM092424 (to the Center for RNA Biology at University of Rochester), and GM-17129 (to H. F.N.). Single-molecule experiments were supported in part by the National Science Foundation Physics Frontiers Center Program through the Center for the Physics of Living Cells (no. 0822613). T.H. is an employee of the Howard Hughes Medical Institute.

Author contributions: D.N.E. conceived the idea. D.N.E. and H.F. N. designed the research. D.N.E. carried out biochemical experiments. P.V.C. and D.N.E. did single-molecule experiments and analyzed the data. D.N.E. and H.F.N. wrote the paper. All authors contributed to the final version of the manuscript.

Received August 13, 2012; accepted November 2, 2012.

\section{REFERENCES}

Agirrezabala X, Lei J, Brunelle JL, Ortiz-Meoz RF, Green R, Frank J. 2008. Visualization of the hybrid state of tRNA binding promoted by spontaneous ratcheting of the ribosome. Mol Cell 32: 190-197.

Blanchard SC, Kim HD, Gonzalez RL Jr, Puglisi JD, Chu S. 2004. tRNA dynamics on the ribosome during translation. Proc Natl Acad Sci 101: 12893-12898.

Borovinskaya MA, Shoji S, Fredrick K, Cate JH. 2008. Structural basis for hygromycin B inhibition of protein biosynthesis. RNA 14: 1590-1599.

Bulkley D, Innis CA, Blaha G, Steitz TA. 2010. Revisiting the structures of several antibiotics bound to the bacterial ribosome. Proc Natl Acad Sci 107: 17158-17163.

Celma ML, Monro RE, Vazquez D. 1971. Substrate and antibiotic binding sites at the peptidyl transferase centre of $E$. coli ribosomes: Binding of UACCA-Leu to 50 S subunits. FEBS Lett 13: 247-251.
Contreras A, Vazquez D. 1977. Cooperative and antagonistic interactions of peptidyl-tRNA and antibiotics with bacterial ribosomes. Eur J Biochem 74: 539-547.

Cornish PV, Ermolenko DN, Noller HF, Ha T. 2008. Spontaneous intersubunit rotation in single ribosomes. Mol Cell 30: 578-588.

Culver GM, Noller HF. 1999. Efficient reconstitution of functional Escherichia coli 30 S ribosomal subunits from a complete set of recombinant small subunit ribosomal proteins. RNA 5: 832-843.

Dorner S, Brunelle JL, Sharma D, Green R. 2006. The hybrid state of tRNA binding is an authentic translation elongation intermediate. Nat Struct Mol Biol 13: 234-241.

Douthwaite S. 1992. Interaction of the antibiotics clindamycin and lincomycin with Escherichia coli $23 \mathrm{~S}$ ribosomal RNA. Nucleic Acids Res 20: $4717-4720$.

Dunkle JA, Xiong L, Mankin AS, Cate JH. 2010. Structures of the Escherichia coli ribosome with antibiotics bound near the peptidyl transferase center explain spectra of drug action. Proc Natl Acad Sci 107: 17152-17157.

Dunkle JA, Wang L, Feldman MB, Pulk A, Chen VB, Kapral GJ, Noeske J, Richardson JS, Blanchard SC, Cate JH. 2011. Structures of the bacterial ribosome in classical and hybrid states of tRNA binding. Science 332: 981-984.

Ermolenko DN, Noller HF. 2011. mRNA translocation occurs during the second step of ribosomal intersubunit rotation. Nat Struct Mol Biol 18: 457-462.

Ermolenko DN, Majumdar ZK, Hickerson RP, Spiegel PC, Clegg RM, Noller HF. 2007a. Observation of intersubunit movement of the ribosome in solution using FRET. J Mol Biol 370: 530-540.

Ermolenko DN, Spiegel PC, Majumdar ZK, Hickerson RP, Clegg RM, Noller HF. 2007b. The antibiotic viomycin traps the ribosome in an intermediate state of translocation. Nat Struct Mol Biol 14: 493-497.

Fei J, Kosuri P, MacDougall DD, Gonzalez RL Jr. 2008. Coupling of ribosomal L1 stalk and tRNA dynamics during translation elongation. Mol Cell 30: 348-359.

Fernandez-Munoz R, Monro RE, Torres-Pinedo R, Vazquez D. 1971. Substrate- and antibiotic-binding sites at the peptidyl-transferase centre of Escherichia coli ribosomes. Studies on the chloramphenicol, lincomycin and erythromycin sites. Eur J Biochem 23: 185-193.

Frank J, Gonzalez RL Jr. 2010. Structure and dynamics of a processive Brownian motor: The translating ribosome. Annu Rev Biochem 79: 381-412.

Fredrick K, Noller HF. 2002. Accurate translocation of mRNA by the ribosome requires a peptidyl group or its analog on the tRNA moving into the 30S P site. Mol Cell 9: 1125-1131.

Fredrick K, Noller HF. 2003. Catalysis of ribosomal translocation by sparsomycin. Science 300: 1159-1162.

Gao YG, Selmer M, Dunham CM, Weixlbaumer A, Kelley AC, Ramakrishnan V. 2009. The structure of the ribosome with elongation factor G trapped in the posttranslocational state. Science 326: 694-699.

Hansen JL, Moore PB, Steitz TA. 2003. Structures of five antibiotics bound at the peptidyl transferase center of the large ribosomal subunit. J Mol Biol 330: 1061-1075.

Hickerson R, Majumdar ZK, Baucom A, Clegg RM, Noller HF. 2005. Measurement of internal movements within the $30 \mathrm{~S}$ ribosomal subunit using Forster resonance energy transfer. J Mol Biol 354: 459-472.

Horan LH, Noller HF. 2007. Intersubunit movement is required for ribosomal translocation. Proc Natl Acad Sci 104: 4881-4885.

Howard J. 2006. Protein power strokes. Curr Biol 16: R517-R519.

Joseph S, Noller HF. 1998. EF-G-catalyzed translocation of anticodon stem-loop analogs of transfer RNA in the ribosome. EMBO J 17: 3478-3483.

Julian P, Konevega AL, Scheres SH, Lazaro M, Gil D, Wintermeyer W, Rodnina MV, Valle M. 2008. Structure of ratcheted ribosomes with tRNAs in hybrid states. Proc Natl Acad Sci 105: 16924 16927. 
Lancaster L, Kiel MC, Kaji A, Noller HF. 2002. Orientation of ribosome recycling factor in the ribosome from directed hydroxyl radical probing. Cell 111: 129-140.

Lazaro E, van den Broek LA, Ottenheijm HC, Lelieveld P, Ballesta JP. 1987. Structure-activity relationships of sparsomycin: Modification at the hydroxyl group. Biochimie 69: 849-856.

Lazaro E, van den Broek LA, San Felix A, Ottenheijm HC, Ballesta JP. 1991. Biochemical and kinetic characteristics of the interaction of the antitumor antibiotic sparsomycin with prokaryotic and eukaryotic ribosomes. Biochemistry 30: 9642-9648.

Li S, Cheng X, Zhou Y, Xi Z. 2011. Sparsomycin-linezolid conjugates can promote ribosomal translocation. Chembiochem 12: 2801-2806.

Lin AH, Murray RW, Vidmar TJ, Marotti KR. 1997. The oxazolidinone eperezolid binds to the 50S ribosomal subunit and competes with binding of chloramphenicol and lincomycin. Antimicrob Agents Chemother 41: 2127-2131.

Martemyanov KA, Yarunin AS, Liljas A, Gudkov AT. 1998. An intact conformation at the tip of elongation factor G domain IV is functionally important. FEBS Lett 434: 205-208.

McKinney SA, Joo C, Ha T. 2006. Analysis of single-molecule FRET trajectories using hidden Markov modeling. Biophys J 91: 1941-1951.

Moazed D, Noller HF. 1989. Intermediate states in the movement of transfer RNA in the ribosome. Nature 342: 142-148.

Monro RE, Celma ML, Vazquez D. 1969. Action of sparsomycin on ribosome-catalysed peptidyl transfer. Nature 222: 356-358.

Munro JB, Altman RB, O'Connor N, Blanchard SC. 2007. Identification of two distinct hybrid state intermediates on the ribosome. Mol Cell 25: 505-517.

Pan D, Kirillov SV, Cooperman BS. 2007. Kinetically competent intermediates in the translocation step of protein synthesis. Mol Cell 25: 519-529.

Peske F, Savelsbergh A, Katunin VI, Rodnina MV, Wintermeyer W. 2004. Conformational changes of the small ribosomal subunit during elongation factor G-dependent tRNA-mRNA translocation. J Mol Biol 343: 1183-1194.

Pestka S. 1969. Studies on the formation of transfer ribonucleic acid-ribosome complexes. XI. Antibiotic effects on phenylalanyl-oligonucleotide binding to ribosomes. Proc Natl Acad Sci 64: 709-714.

Rasnik I, McKinney SA, Ha T. 2006. Nonblinking and long-lasting single-molecule fluorescence imaging. Nat Methods 3: 891-893.
Ratje AH, Loerke J, Mikolajka A, Brunner M, Hildebrand PW, Starosta AL, Donhofer A, Connell SR, Fucini P, Mielke T, et al. 2010. Head swivel on the ribosome facilitates translocation by means of intra-subunit tRNA hybrid sites. Nature 468: 713-716.

Rodnina MV, Savelsbergh A, Katunin VI, Wintermeyer W. 1997. Hydrolysis of GTP by elongation factor G drives tRNA movement on the ribosome. Nature 385: 37-41.

Schlunzen F, Zarivach R, Harms J, Bashan A, Tocilj A, Albrecht R, Yonath A, Franceschi F. 2001. Structural basis for the interaction of antibiotics with the peptidyl transferase centre in eubacteria. Nature 413: 814-821.

Schuwirth BS, Borovinskaya MA, Hau CW, Zhang W, Vila-Sanjurjo A, Holton JM, Cate JH. 2005. Structures of the bacterial ribosome at 3.5 Å resolution. Science 310: 827-834.

Spiegel PC, Ermolenko DN, Noller HF. 2007. Elongation factor G stabilizes the hybrid-state conformation of the 70 S ribosome. RNA 13: 1473-1482.

Spirin AS. 2004. The ribosome as an RNA-based molecular machine. RNA Biol 1: 3-9.

Stanley RE, Blaha G, Grodzicki RL, Strickler MD, Steitz TA. 2010. The structures of the anti-tuberculosis antibiotics viomycin and capreomycin bound to the 70S ribosome. Nat Struct Mol Biol 17: 289-293.

Valle M, Zavialov A, Sengupta J, Rawat U, Ehrenberg M, Frank J. 2003. Locking and unlocking of ribosomal motions. Cell 114: 123134.

Wilson DN. 2009. The A-Z of bacterial translation inhibitors. Crit Rev Biochem Mol Biol 44: 393-433.

Wilson KS, Noller HF. 1998. Mapping the position of translational elongation factor EF-G in the ribosome by directed hydroxyl radical probing. Cell 92: 131-139.

Wohlgemuth I, Beringer M, Rodnina MV. 2006. Rapid peptide bond formation on isolated 50 S ribosomal subunits. EMBO Rep 7: 699703.

Zhou J, Lancaster L, Trakhanov S, Noller HF. 2012. Crystal structure of release factor RF3 trapped in the GTP state on a rotated conformation of the ribosome. RNA 18: 230-240.

Zhuang X, Bartley LE, Babcock HP, Russell R, Ha T, Herschlag D, Chu S. 2000. A single-molecule study of RNA catalysis and folding. Science 288: 2048-2051. 

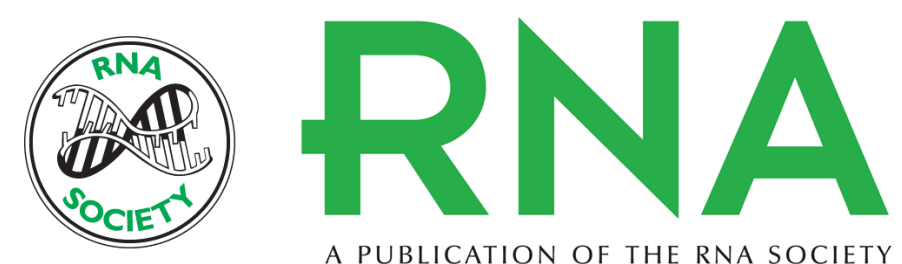

A PUBLICATION OF THE RNA SOCIETY

\section{Antibiotics that bind to the A site of the large ribosomal subunit can induce mRNA translocation}

Dmitri N. Ermolenko, Peter V. Cornish, Taekjip Ha, et al.

RNA 2013 19: 158-166 originally published online December 17, 2012

Access the most recent version at doi:10.1261/rna.035964.112

$\begin{array}{ll}\text { References } & \begin{array}{l}\text { This article cites } 54 \text { articles, } 17 \text { of which can be accessed free at: } \\ \text { http://rnajournal.cshlp.org/content/19/2/158.full.html\#ref-list-1 }\end{array}\end{array}$

License

Email Alerting Receive free email alerts when new articles cite this article - sign up in the box at the Service top right corner of the article or click here.

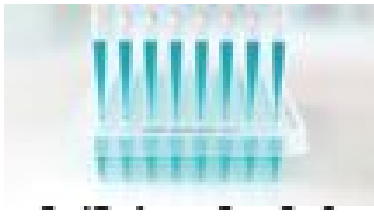

Providing Precise Solutions for your research.

To subscribe to RNA go to:

http://rnajournal.cshlp.org/subscriptions 